\title{
Linear Transformations of Euclidean Topological Spaces
}

\author{
Karol Pąk \\ Institute of Informatics \\ University of Białystok \\ Poland
}

\begin{abstract}
Summary. We introduce linear transformations of Euclidean topological spaces given by a transformation matrix. Next, we prove selected properties and basic arithmetic operations on these linear transformations. Finally, we show that a linear transformation given by an invertible matrix is a homeomorphism.
\end{abstract}

MML identifier: MATRTOP1, version: $\underline{7.11 .07 \quad 4.156 .1112}$

The papers [2], [12], [6], [26], [7], [8], [30], [21], [22], [23], [15], [31], [29], [19], $[24],[3],[4],[9],[16],[5],[20],[18],[1],[14],[28],[13],[10],[25],[27],[11]$, and $[17]$ provide the notation and terminology for this paper.

\section{Preliminaries}

For simplicity, we adopt the following rules: $X, Y$ denote sets, $n, m, k, i$ denote natural numbers, $r$ denotes a real number, $R$ denotes an element of $\mathbb{R}_{\mathrm{F}}$, $K$ denotes a field, $f, f_{1}, f_{2}, g_{1}, g_{2}$ denote finite sequences, $r_{1}, r_{2}, r_{3}$ denote real-valued finite sequences, $c_{1}, c_{2}$ denote complex-valued finite sequences, and $F$ denotes a function.

Let us consider $X, Y$ and let $F$ be a positive yielding partial function from $X$ to $\mathbb{R}$. One can check that $F\lceil Y$ is positive yielding.

Let us consider $X, Y$ and let $F$ be a negative yielding partial function from $X$ to $\mathbb{R}$. One can verify that $F\lceil Y$ is negative yielding.

Let us consider $X, Y$ and let $F$ be a non-positive yielding partial function from $X$ to $\mathbb{R}$. Note that $F\lceil Y$ is non-positive yielding. 
Let us consider $X, Y$ and let $F$ be a non-negative yielding partial function from $X$ to $\mathbb{R}$. Note that $F\lceil Y$ is non-negative yielding.

Let us consider $r_{1}$. One can check that $\sqrt{r_{1}}$ is finite sequence-like.

Let us consider $r_{1}$. The functor ${ }^{\circledR} r_{1}$ yielding a finite sequence of elements of $\mathbb{R}_{\mathrm{F}}$ is defined by:

(Def. 1) ${ }^{\circledR} r_{1}=r_{1}$.

Let $p$ be a finite sequence of elements of $\mathbb{R}_{\mathrm{F}}$. The functor ${ }^{@} p$ yields a finite sequence of elements of $\mathbb{R}$ and is defined as follows:

(Def. 2) ${ }^{\circledR} p=p$.

We now state several propositions:

(1) $\left({ }^{@} r_{2}\right)+{ }^{@} r_{3}=r_{2}+r_{3}$.

(2) $\sqrt{r_{2} \frown r_{3}}=\sqrt{r_{2}} \frown \sqrt{r_{3}}$.

(3) $\sqrt{\langle r\rangle}=\langle\sqrt{r}\rangle$.

(4) $\sqrt{r_{1}^{2}}=\left|r_{1}\right|$.

(5) If $r_{1}$ is non-negative yielding, then $\sqrt{\sum r_{1}} \leq \sum \sqrt{r_{1}}$.

(6) There exists $X$ such that $X \subseteq \operatorname{dom} F$ and $\operatorname{rng} F=\operatorname{rng}(F\lceil X)$ and $F \uparrow X$ is one-to-one.

Let us consider $c_{1}, X$. Observe that $c_{1}-X$ is complex-valued.

Let us consider $r_{1}, X$. Observe that $r_{1}-X$ is real-valued.

Let $c_{1}$ be a complex-valued finite subsequence. Note that $\operatorname{Seq} c_{1}$ is complexvalued.

Let $r_{1}$ be a real-valued finite subsequence. Observe that Seq $r_{1}$ is real-valued.

One can prove the following propositions:

(7) For every permutation $P$ of $\operatorname{dom} f$ such that $f_{1}=f \cdot P$ there exists a permutation $Q$ of $\operatorname{dom}(f-X)$ such that $f_{1}-X=(f-X) \cdot Q$.

(8) For every permutation $P$ of $\operatorname{dom} c_{1}$ such that $c_{2}=c_{1} \cdot P$ holds $\sum\left(c_{2}-\right.$ $X)=\sum\left(c_{1}-X\right)$.

(9) Let $f, f_{1}$ be finite subsequences and $P$ be a permutation of $\operatorname{dom} f$. If $f_{1}=f \cdot P$, then there exists a permutation $Q$ of $\operatorname{dom} \operatorname{Seq}\left(f_{1} \backslash P^{-1}(X)\right)$ such that $\operatorname{Seq}\left(f\lceil X)=\operatorname{Seq}\left(f_{1}\left\lceil P^{-1}(X)\right) \cdot Q\right.\right.$.

(10) Let $c_{1}, c_{2}$ be complex-valued finite subsequences and $P$ be a permutation of $\operatorname{dom} c_{1}$. If $c_{2}=c_{1} \cdot P$, then $\sum \operatorname{Seq}\left(c_{1}\lceil X)=\sum \operatorname{Seq}\left(c_{2}\left\lceil P^{-1}(X)\right)\right.\right.$.

(11) Let $f$ be a finite subsequence and $n$ be an element of $\mathbb{N}$. If for every $i$ holds $i+n \in X$ iff $i \in Y$, then $\operatorname{Shift}^{n} f\left\lceil X=\operatorname{Shift}^{n}(f \backslash Y)\right.$.

(12) There exists a subset $Y$ of $\mathbb{N}$ such that $\operatorname{Seq}\left(\left(f_{1} \frown f_{2}\right)\lceil X)=\left(\operatorname{Seq}\left(f_{1}\lceil X)\right)^{\frown}\right.\right.$ $\operatorname{Seq}\left(f_{2} \backslash Y\right)$ and for every $n$ such that $n>0$ holds $n \in Y$ iff $n+\operatorname{len} f_{1} \in$ $X \cap \operatorname{dom}\left(f_{1} \frown f_{2}\right)$.

(13) If len $g_{1}=\operatorname{len} f_{1}$ and len $g_{2} \leq \operatorname{len} f_{2}$, then $\operatorname{Seq}\left(\left(f_{1} \frown f_{2}\right)\left\lceil\left(g_{1} \frown g_{2}\right)^{-1}(X)\right)=\right.$ $\left(\operatorname{Seq}\left(f_{1}\left\lceil g_{1}^{-1}(X)\right)\right) \frown \operatorname{Seq}\left(f_{2}\left\lceil g_{2}^{-1}(X)\right)\right.\right.$. 
(14) Let $D$ be a non empty set and $M$ be a matrix over $D$ of dimension $n \times$ $m$. Then $M-X$ is a matrix over $D$ of dimension $n-^{\prime} \overline{\overline{M^{-1}(X)}} \times m$.

(15) Let $F$ be a function from $\operatorname{Seg} n$ into $\operatorname{Seg} n, D$ be a non empty set, $M$ be a matrix over $D$ of dimension $n \times m$, and given $i$. If $i \in \operatorname{Seg}$ width $M$, then $(M \cdot F)_{\square, i}=M_{\square, i} \cdot F$.

(16) Let $A$ be a matrix over $K$ of dimension $n \times m$. Suppose $\operatorname{rk}(A)=n$. Then there exists a matrix $B$ over $K$ of dimension $m-^{\prime} n \times m$ such that $\operatorname{rk}\left(A^{\frown} B\right)=m$.

(17) Let $A$ be a matrix over $K$ of dimension $n \times m$. Suppose $\operatorname{rk}(A)=m$. Then there exists a matrix $B$ over $K$ of dimension $n \times n-^{\prime} m$ such that $\operatorname{rk}(A \frown B)=n$.

For simplicity, we adopt the following convention: $f, f_{1}, f_{2}$ denote $n$-element real-valued finite sequences, $p, p_{1}, p_{2}$ denote points of $\mathcal{E}_{\mathrm{T}}^{n}, M, M_{1}, M_{2}$ denote matrices over $\mathbb{R}_{\mathrm{F}}$ of dimension $n \times m$, and $A, B$ denote square matrices over $\mathbb{R}_{\mathrm{F}}$ of dimension $n$.

\section{Linear Transformations of Euclidean Topological Spaces Given By a TRANSFORMation MatriX}

Let us consider $n, m, M$. The functor Mx2Tran $M$ yielding a function from $\mathcal{E}_{\mathrm{T}}^{n}$ into $\mathcal{E}_{\mathrm{T}}^{m}$ is defined by:

(Def. 3)(i) $\quad(\operatorname{Mx} 2 \operatorname{Tran} M)(f)=\operatorname{Line}\left(\operatorname{LineVec} 2 \mathrm{Mx}\left({ }^{@} f\right) \cdot M, 1\right)$ if $n \neq 0$,

(ii) $\quad(\mathrm{Mx} 2 \operatorname{Tran} M)(f)=0_{\mathcal{E}_{\mathrm{T}}^{m}}$, otherwise.

Let us consider $n, m, M$ and let $x$ be a set. One can check that $(\operatorname{Mx} 2 \operatorname{Tran} M)(x)$ is function-like and relation-like and $(\operatorname{Mx} 2 \operatorname{Tran} M)(x)$ is real-valued and finite sequence-like.

Let us consider $n, m, M, f$. One can check that $(\operatorname{Mx} 2 \operatorname{Tran} M)(f)$ is $m$ element.

One can prove the following propositions:

(18) If $1 \leq i \leq m$ and $n \neq 0$, then $(\operatorname{Mx} 2 \operatorname{Tran} M)(f)(i)=\left({ }^{@} f\right) \cdot M_{\square, i}$.

(19) len $\operatorname{MX} 2 \operatorname{FinS}\left(I_{K}^{n \times n}\right)=n$.

(20) Let $B_{1}$ be an ordered basis of the $n$-dimension vector space over $\mathbb{R}_{\mathrm{F}}$ and $B_{2}$ be an ordered basis of the $m$-dimension vector space over $\mathbb{R}_{\mathrm{F}}$. Suppose $B_{1}=\operatorname{MX} 2 \operatorname{FinS}\left(I_{\mathbb{R}_{\mathrm{F}}}^{n \times n}\right)$ and $B_{2}=\operatorname{MX} 2 \operatorname{FinS}\left(I_{\mathbb{R}_{\mathrm{F}}}^{m \times m}\right)$. Let $M_{1}$ be a matrix over $\mathbb{R}_{\mathrm{F}}$ of dimension len $B_{1} \times$ len $B_{2}$. If $M_{1}=M$, then $\mathrm{Mx} 2 \operatorname{Tran} M=$ $\operatorname{Mx} 2 \operatorname{Tran}\left(M_{1}, B_{1}, B_{2}\right)$.

(21) For every permutation $P$ of $\operatorname{Seg} n$ holds $(\operatorname{Mx} 2 \operatorname{Tran} M)(f)=$ $(\mathrm{Mx} 2 \operatorname{Tran}(M \cdot P))(f \cdot P)$ and $f \cdot P$ is an $n$-element finite sequence of elements of $\mathbb{R}$.

(22) $(\operatorname{Mx} 2 \operatorname{Tran} M)\left(f_{1}+f_{2}\right)=(\operatorname{Mx} 2 \operatorname{Tran} M)\left(f_{1}\right)+(\operatorname{Mx} 2 \operatorname{Tran} M)\left(f_{2}\right)$. 
(23) $(\operatorname{Mx} 2 \operatorname{Tran} M)(r \cdot f)=r \cdot(\operatorname{Mx} 2 \operatorname{Tran} M)(f)$.

(24) $\quad(\mathrm{Mx} 2 \operatorname{Tran} M)\left(f_{1}-f_{2}\right)=(\operatorname{Mx} 2 \operatorname{Tran} M)\left(f_{1}\right)-(\operatorname{Mx} 2 \operatorname{Tran} M)\left(f_{2}\right)$.

(25) $\left(\operatorname{Mx} 2 \operatorname{Tran}\left(M_{1}+M_{2}\right)\right)(f)=\left(\mathrm{Mx} 2 \operatorname{Tran} M_{1}\right)(f)+\left(\mathrm{Mx} 2 \operatorname{Tran} M_{2}\right)(f)$.

(26) $(R) \cdot(\operatorname{Mx} 2 \operatorname{Tran} M)(f)=(\operatorname{Mx} 2 \operatorname{Tran}(R \cdot M))(f)$.

(27) $(\operatorname{Mx} 2 \operatorname{Tran} M)\left(p_{1}+p_{2}\right)=(\operatorname{Mx} 2 \operatorname{Tran} M)\left(p_{1}\right)+(\operatorname{Mx} 2 \operatorname{Tran} M)\left(p_{2}\right)$.

(28) $(\operatorname{Mx} 2 \operatorname{Tran} M)\left(p_{1}-p_{2}\right)=(\operatorname{Mx} 2 \operatorname{Tran} M)\left(p_{1}\right)-(\operatorname{Mx} 2 \operatorname{Tran} M)\left(p_{2}\right)$.

(29) $(\operatorname{Mx} 2 \operatorname{Tran} M)\left(0_{\mathcal{E}_{\mathrm{T}}^{n}}\right)=0_{\mathcal{E}_{\mathrm{T}}^{m}}$.

(30) For every subset $A$ of $\mathcal{E}_{\mathrm{T}}^{n}$ holds $(\operatorname{Mx} 2 \operatorname{Tran} M)^{\circ}(p+A)=$ $(\operatorname{Mx} 2 \operatorname{Tran} M)(p)+(\operatorname{Mx} 2 \operatorname{Tran} M)^{\circ} A$.

(31) For every subset $A$ of $\mathcal{E}_{\mathrm{T}}^{m}$ holds $(\mathrm{Mx} 2 \operatorname{Tran} M)^{-1}((\mathrm{Mx} 2 \operatorname{Tran} M)(p)+A)=$ $p+(\operatorname{Mx} 2 \operatorname{Tran} M)^{-1}(A)$.

(32) Let $A$ be a matrix over $\mathbb{R}_{\mathrm{F}}$ of dimension $n \times m$ and $B$ be a matrix over $\mathbb{R}_{\mathrm{F}}$ of dimension width $A \times k$. If if $n=0$, then $m=0$ and if $m=0$, then $k=0$, then $\mathrm{Mx} 2 \operatorname{Tran} B \cdot \operatorname{Mx} 2 \operatorname{Tran} A=\operatorname{Mx} 2 \operatorname{Tran}(A \cdot B)$.

(33) $\operatorname{Mx} 2 \operatorname{Tran}\left(I_{\mathbb{R}_{\mathrm{F}}}^{n \times n}\right)=\operatorname{id}_{\mathcal{E}_{\mathrm{T}}^{n}}$.

(34) If Mx2Tran $M_{1}=\operatorname{Mx} 2 \operatorname{Tran} M_{2}$, then $M_{1}=M_{2}$.

(35) Let $A$ be a matrix over $\mathbb{R}_{\mathrm{F}}$ of dimension $n \times m$ and $B$ be a matrix over $\mathbb{R}_{\mathrm{F}}$ of dimension $k \times m$. Then $\left(\operatorname{Mx} 2 \operatorname{Tran}\left(A^{\frown} B\right)\right)\left(f^{\frown}(k \mapsto 0)\right)=$ $(\operatorname{Mx} 2 \operatorname{Tran} A)(f)$ and $\left(\operatorname{Mx} 2 \operatorname{Tran}\left(B^{\frown} A\right)\right)\left((k \mapsto 0)^{\frown} f\right)=(\operatorname{Mx} 2 \operatorname{Tran} A)(f)$.

(36) Let $A$ be a matrix over $\mathbb{R}_{\mathrm{F}}$ of dimension $n \times m, B$ be a matrix over $\mathbb{R}_{\mathrm{F}}$ of dimension $k \times m$, and $g$ be a $k$-element real-valued finite sequence. Then $\left(\operatorname{Mx} 2 \operatorname{Tran}\left(A^{\frown} B\right)\right)\left(f^{\frown} g\right)=(\operatorname{Mx} 2 \operatorname{Tran} A)(f)+(\operatorname{Mx} 2 \operatorname{Tran} B)(g)$.

(37) Let $A$ be a matrix over $\mathbb{R}_{\mathrm{F}}$ of dimension $n \times k$ and $B$ be a matrix over $\mathbb{R}_{\mathrm{F}}$ of dimension $n \times m$ such that if $n=0$, then $k+m=0$. Then $(\operatorname{Mx} 2 \operatorname{Tran}(A \frown B))(f)=(\operatorname{Mx} 2 \operatorname{Tran} A)(f)^{\frown}(\operatorname{Mx} 2 \operatorname{Tran} B)(f)$.

(38) $\left(\operatorname{Mx} 2 \operatorname{Tran}\left(I_{\mathbb{R}_{\mathrm{F}}}^{m \times m}\lceil n)\right)(f)\lceil n=f\right.$.

\section{Selected Properties of the Mx2Tran Operator}

Next we state several propositions:

(39) $\operatorname{Mx} 2 \operatorname{Tran} M$ is one-to-one iff $\operatorname{rk}(M)=n$.

(40) $\quad \mathrm{Mx} 2 \operatorname{Tran} A$ is one-to-one iff $\operatorname{Det} A \neq 0_{\mathbb{R}_{\mathrm{F}}}$.

(41) $\mathrm{Mx} 2 \operatorname{Tran} M$ is onto iff $\operatorname{rk}(M)=m$.

(42) $\mathrm{Mx} 2 \operatorname{Tran} A$ is onto iff $\operatorname{Det} A \neq 0_{\mathbb{R}_{\mathrm{F}}}$.

(43) For all $A, B$ such that Det $A \neq 0_{\mathbb{R}_{\mathrm{F}}}$ holds $(\operatorname{Mx} 2 \operatorname{Tran} A)^{-1}=\operatorname{Mx} 2 \operatorname{Tran} B$ iff $A^{\smile}=B$.

(44) There exists an $m$-element finite sequence $L$ of elements of $\mathbb{R}$ such that for every $i$ such that $i \in \operatorname{dom} L$ holds $L(i)=\left|{ }^{\circledR}\left(M_{\square, i}\right)\right|$ and for every $f$ holds $|(\operatorname{Mx} 2 \operatorname{Tran} M)(f)| \leq \sum L \cdot|f|$. 
(45) There exists a real number $L$ such that $L>0$ and for every $f$ holds $|(\operatorname{Mx} 2 \operatorname{Tran} M)(f)| \leq L \cdot|f|$.

(46) If $\operatorname{rk}(M)=n$, then there exists a real number $L$ such that $L>0$ and for every $f$ holds $|f| \leq L \cdot|(\mathrm{Mx} 2 \operatorname{Tran} M)(f)|$.

(47) $\mathrm{Mx} 2 \operatorname{Tran} M$ is continuous.

Let us consider $n, K$. One can check that there exists a square matrix over $K$ of dimension $n$ which is invertible.

Let us consider $n$ and let $A$ be an invertible square matrix over $\mathbb{R}_{\mathrm{F}}$ of dimension $n$. Note that Mx2Tran $A$ is homeomorphism.

\section{REFERENCES}

[1] Jesse Alama. The rank+nullity theorem. Formalized Mathematics, 15(3):137-142, 2007, doi:10.2478/v10037-007-0015-6.

[2] Grzegorz Bancerek. Cardinal numbers. Formalized Mathematics, 1(2):377-382, 1990.

[3] Grzegorz Bancerek. The fundamental properties of natural numbers. Formalized Mathematics, 1(1):41-46, 1990.

[4] Grzegorz Bancerek. The ordinal numbers. Formalized Mathematics, 1(1):91-96, 1990.

[5] Grzegorz Bancerek, Mitsuru Aoki, Akio Matsumoto, and Yasunari Shidama. Processes in Petri nets. Formalized Mathematics, 11(1):125-132, 2003.

[6] Grzegorz Bancerek and Krzysztof Hryniewiecki. Segments of natural numbers and finite sequences. Formalized Mathematics, 1(1):107-114, 1990.

[7] Czesław Byliński. Functions and their basic properties. Formalized Mathematics, 1(1):5565, 1990.

[8] Czesław Byliński. Functions from a set to a set. Formalized Mathematics, 1(1):153-164, 1990.

9] Czesław Byliński. Partial functions. Formalized Mathematics, 1(2):357-367, 1990.

[10] Czesław Byliński. The sum and product of finite sequences of real numbers. Formalized Mathematics, 1(4):661-668, 1990.

[11] Agata Darmochwał. Families of subsets, subspaces and mappings in topological spaces. Formalized Mathematics, 1(2):257-261, 1990.

[12] Agata Darmochwał. The Euclidean space. Formalized Mathematics, 2(4):599-603, 1991.

[13] Noboru Endou, Takashi Mitsuishi, and Yasunari Shidama. Dimension of real unitary space. Formalized Mathematics, 11(1):23-28, 2003.

[14] Krzysztof Hryniewiecki. Basic properties of real numbers. Formalized Mathematics, 1(1):35-40, 1990.

[15] Katarzyna Jankowska. Matrices. Abelian group of matrices. Formalized Mathematics, 2(4):475-480, 1991.

[16] Artur Korniłowicz. On the real valued functions. Formalized Mathematics, 13(1):181-187, 2005.

[17] Eugeniusz Kusak, Wojciech Leończuk, and Michał Muzalewski. Abelian groups, fields and vector spaces. Formalized Mathematics, 1(2):335-342, 1990.

[18] Anna Lango and Grzegorz Bancerek. Product of families of groups and vector spaces. Formalized Mathematics, 3(2):235-240, 1992.

[19] Robert Milewski. Associated matrix of linear map. Formalized Mathematics, 5(3):339345, 1996

[20] Beata Padlewska and Agata Darmochwał. Topological spaces and continuous functions. Formalized Mathematics, 1(1):223-230, 1990.

[21] Karol Pąk. Basic properties of determinants of square matrices over a field. Formalized Mathematics, 15(1):17-25, 2007, doi:10.2478/v10037-007-0003-x.

[22] Karol Pąk. Basic properties of the rank of matrices over a field. Formalized Mathematics, 15(4):199-211, 2007, doi:10.2478/v10037-007-0024-5.

[23] Karol Pąk. Solutions of linear equations. Formalized Mathematics, 16(1):81-90, 2008, doi:10.2478/v10037-008-0012-4. 
[24] Karol Pąk. Linear map of matrices. Formalized Mathematics, 16(3):269-275, 2008, doi:10.2478/v10037-008-0032-0.

[25] Andrzej Trybulec and Czesław Byliński. Some properties of real numbers. Formalized Mathematics, 1(3):445-449, 1990.

[26] Wojciech A. Trybulec. Non-contiguous substrings and one-to-one finite sequences. Formalized Mathematics, 1(3):569-573, 1990.

[27] Zinaida Trybulec. Properties of subsets. Formalized Mathematics, 1(1):67-71, 1990.

[28] Edmund Woronowicz. Relations and their basic properties. Formalized Mathematics, 1(1):73-83, 1990.

[29] Xiaopeng Yue, Xiquan Liang, and Zhongpin Sun. Some properties of some special matrices. Formalized Mathematics, 13(4):541-547, 2005.

[30] Katarzyna Zawadzka. The sum and product of finite sequences of elements of a field. Formalized Mathematics, 3(2):205-211, 1992.

[31] Katarzyna Zawadzka. The product and the determinant of matrices with entries in a field. Formalized Mathematics, 4(1):1-8, 1993.

Received October 26, 2010 